\title{
Spontaneous Hemoperitoneum from a Ruptured Superficial Uterine Vessel in Third Trimester of Pregnancy
}

\author{
KHAIRUN NAHAR ${ }^{1}$, HAMIDA BEGUM $^{2}$, MAHMUDA KHATUN ${ }^{3}$
}

\begin{abstract}
Summary:
Spontaneous hemoperitoneum in third trimester of pregnancy is a very rare but lethal condition which demands prompt diagnosis and management for the survival of both mother and fetus. A 30 years old multipara woman presented at 34 weeks of pregnancy with acute abdominal pain and hypovolemic shock. Emergency exploratory laparotomy was done; an asphyxiated baby was born by cesarean section. One of multiple engorged superficial vessels on posterior surface of the uterus was found bleeding actively, which was then sutured. Post operative recovery of the patient was good.
\end{abstract}

\section{Introduction:}

Hemoperitoneum during pregnancy is rare but potentially life threatening to both mother and fetus. Spontaneous hemoperitoneum may develop from rupture of various abdominal or pelvic structures including the spleen, uterus, uterine vessels, ovarian vessels or pelvic endometrial implants ${ }^{1}$. It mimics placental abruption in many ways. Important features are acute abdominal pain, peritonitis, shock, fetal distress or death ${ }^{2}$. Appropriate volume replacement and immediate surgical intervention provides the best prognosis. Here, a case of spontaneous hemoperitoneum during third trimester of pregnancy is reported. The objective of this report is to share the experience of the diagnosis and management of a rare but acute surgical condition in pregnancy.

\section{Case report:}

A 30 years old, $4^{\text {th }}$ gravida,para(2+1) housewife admitted in Sir Salimullah Medical College, Mitford Hospital with 34 weeks pregnancy and acute pain in abdomen for few hours without any history of trauma. She had no history of previous cesarean section. She had no antenatal check-up. On examination, she was severely anaemic, blood pressure was $90 / 50 \mathrm{~mm}$ of $\mathrm{Hg}$, pulse rate was $112 / \mathrm{min}$. Abdomen was found tender and height of uterus was $34 \mathrm{~cm}$, FHS could not be well elicited due to tenderness and rigidity of abdomen. On P/V examination cervical os was found closed and there was no per vaginal bleeding. As the hemodynamic status of the patient was gradually deteriorating emergency exploratory laparotomy was done with clinical impression of abruptio placenta. On opening the abdomen there was found profuse amount of free blood within the peritoneal cavity which was simulating a ruptured uterus although there was neither history of labour pain nor previous cesarean section which may result into rupture. During removal of huge amount of blood from the peritoneal cavity uterus was thoroughly palpated to exclude any ruptured site. As the uterus was found intact it was very quickly opened by low transverse incision and an alive but severely asphyxiated baby of $2.5 \mathrm{Kg}$ was born. After proper closure of the uterine incision all the susceptible abdominal and pelvic organs were checked to find out the source of bleeding. During thorough examination multiple tortuous engorged superficial vessels were found on the posterior surface of the lower segment of the uterus, one of which was bleeding actively. The bleeding vessel was secured by a very simple mattress suture. Then after proper peritoneal toileting abdomen was closed in layers. Total 3 units of whole blood were transfused during operation. The patient had a good post-operative recovery and she was discharged with her baby on the $6^{\text {th }}$ post-operative day.

\section{Discussion:}

Hemoperitoneum, a life threatening condition may occur in anybody following severe abdominal trauma

1. Assistant Professor,Dept. of Obs.\& Gynae,BSMMU,Dhaka.

2. Assistant Professor,Dept. of Obs.\& Gynae,BSMMU,Dhaka.

3. Professor,Dept. of Obs.\& Gynae,SSMC,MH ,Dhaka. 
causing laceration of any vessel specially if there is varicosity or aneurism. It is not uncommon during early pregnancy, the major cause of which is ruptured ectopic pregnancy. But spontaneous hemoperitoneum during $2^{\text {nd }}$ or $3^{\text {rd }}$ trimester of pregnancy is very rare. Review of literature reveals very few numbers of such cases. Two cases were reported by Thanapan Choobun MD et.al. where intra-abdominal bleeding was due to rupture of ovarian venous plexus during the $2^{\text {nd }} \& 3^{\text {rd }}$ trimester of pregnancy ${ }^{1}$. One case had repeated bleeding at $24 \& 31$ weeks of pregnancy. Emergency exploratory laparotomy and sutureligation were done in both the cases, with LSCS in one case. Primary diagnosis of ruptured utero-ovarian vessel is rare. The pre-operative diagnosis is usually placental abruption in a significant number of cases $(26 \%)^{2}$.In literature utero-ovarian vessel rupture has been reported to be usual in $3^{\text {rd }}$ trimester ${ }^{3}$, but has been shown to occur in all trimesters and puerperium ${ }^{4}$. Though uterine arterio venous malformation is a rare condition, the spontaneous rupture of this was reported by Simpson et.al. as a cause of an acute abdomen in late pregnancy ${ }^{5}$.An atypical case of subacute uterine artery rupture was reported in a 28 years old nulliparous lady with sickle cell anaemia at 27 weeks pregnancy by Fiori $O$ et.al. which was successfully treated by selective suture after laparotomy ${ }^{6}$.Aziz $U$ et. al. reported a case of hemoperitoneum at 20 weeks of gestation resulting from spontaneous rupture of left uterine vessels associated with decidualized endometriosis ${ }^{7}$. Spontaneous rupture of uterine artery in $3^{\text {rd }}$ trimester of pregnancy without any associated pathology also was reported by Swaegers MC et.al. ${ }^{8}$.A case of spontaneous hemoperitoneum was also reported occurring four hours after vaginal delivery, where bleeding was due to avulsion of a fibrous band between the right fallopian tube and uterus ${ }^{9}$.Idiopathic spontaneous hemoperitoneum was also described by Arie Koifman et.al. where origin of the hemorrhage remained obscure even after thorough exploration ${ }^{10}$. An almost similar to the present one another case was reported by $\mathrm{Wu} \mathrm{CY}$ et. al.where source of bleeding was a ruptured superficial vein located on the posterior surface of the uterus ${ }^{11}$. That patient was a 31years old nullipara, presented at 32 weeks while she was on tocolytic drugs. The clinical features led to an impression of abruptio placenta and emergency cesarean section was performed, internal bleeding was about $3 \mathrm{~L}$. After thorough exploration the bleeder was identified and sutured. Maternal and fetal outcome was good. Another case of spontaneous rupture of uterine surface varicose veins was reported by Hashimoto K et. al. where hysterectomy was required due to difficulty in hemostasis of multiple bleeding vessels on the posterior surface of the uterus ${ }^{12}$.

Pathogenesis of spontaneous hemoperitoneum is obscure. Physiological increase in blood flow to the utero-ovarian vessels may cause dilatation of these plexuses and predispose to spontaneous rupture. The sudden increase in intravenous pressure associated with increased intra-abdominal pressure can also cause rupture $^{3,7}$.Principle of management includes immediate resuscitation and exploratory laparotomy. At first, the bleeding point must be tried to be found by meticulous manipulation of uterus and other organs to ligate it. If the uterus is found too large to manipulate, prompt cesarean section should be done, so that the bleeding site can easily be found. If no pelvic pathology is found, other important vulnerable vessels like splenic, hepatic, renal or any aneurismal vessel should be inspected.

\section{Conclusion:}

Although very rare, obstetricians should be aware of this cause of acute abdominal pain and hypovolaemic shock in pregnancy. Close observation, prompt diagnosis, and proper intervention are the keys to patient survival. The use of sophisticated techniques of anaesthesia and volume replacement as well as modern advanced neonatal care has tremendous role in improvement of maternal and fetal outcome. There is an important field of study to find out prevalence and pathogenesis of this life threatening condition.

\section{References:}

1. Thanapan Choobun MD, Sutham PinjaroenMD, Chatpavit Getpook MD. Spontaneous IntraAbdominal Bleeding during Pregnancy:J Med Assoc Thai 2006; 87 (7): 1044-6.

2. Ginsburg KA, Valdes C, Schnider G. Spontaneous utero-ovarian vessel rupture during pregnancy: three case reports and a review of the literature. Obstet Gynecol 1987; 69: 474-6.

3. Foley MR, Sonek JD, and Lavender M, Zuspal FP. Spontaneous rupture of utero-ovarian veins in pregnancy: two case reports. Am J Obstet Gynecol 1987; 156: 962-4. 
4. Liu CM, Hsu JJ, Hsieh TT, Soong YK. Postpartum hemorrhage of the uterine artery. Acta Obstet Gynecol Scand 1998;77:695-7.

5. Simpson I,Ng A, Griffin C. A rare cause of an acute abdomen in late pregnancy. Aust NZ J Obstet Gynecol 1995;35:435-6.

6. Fiori O, Pruqnolles H, Darai E. Spontaneous uterine artery rupture during pregnancy in a woman with sickle cell disease: a case report. J Reprod Med. 2007;52(7): 657-8.

7. Aziz U, Kulkarni A, Lazic D,Cullimore JE. Spontaneous rupture of the uterine vessels in pregnancy. Obstet Gynecol 2004;103:1089-91.

8. Swaegers MC, Hauspy JJ, Buytaert PM, De Maeseneer MG. Spontaneous rupture of the uterine artery in pregnancy. Eur. J Obstet Gynecol Reprod Biol 1997;75: 145-6.
9. Fu, Hung-Chung; Ko, Sheung-Fat; Ou, Chia-Yu; Hsu, Te-Yao.Postpartum hemoperitoneum due to avulsion of pelvic adhesion band. Southern Medical Journal 2006; 99: 11.

10. Arie Koifman, Adi Y. Weintraub, David Segal. Idiopathic spontaneous hemoperitoneum during pregnancy.Archives of Gynecology and Obstetrics 2006; 276: 269-70.

11. Wu CY,Hwanq JL, Liu YH, Hsieu BC. Spontaneous hemoperitoneum in pregnancy from a ruptured superficial uterine vessel. Taiwan J Obstet Gynecol 2007;46: 77-80.

12. Hashimoto K, Tabata C, Ueno Y, Fukuda H. Spontaneous rupture of uterine surface varicose veins in pregnancy: a case report. J Reprod Med 2006; 51: 722-4. 